\title{
ALFABETIZAÇÃO: O OLHAR DAS CRIANÇAS SOBRE O APRENDIZADO DA LINGUAGEM ESCRITA
}

\author{
Angela Vidal Gonçalves*
}

\begin{abstract}
RESUMO: O artigo apresenta resultados de uma pesquisa realizada com crianças do primeiro ano do ensino fundamental, em escola pública federal, no Rio de Janeiro, durante o ano de 2011, cujo objetivo geral é conhecer as concepçōes que crianças elaboram sobre o processo de alfabetização, antes e depois de serem alfabetizadas. Realizaram-se entrevistas com as crianças, os pais e a professora da turma. A análise dos discursos dos sujeitos participantes se baseou na Teoria da Enunciação de Bakhtin. Recorreu-se ainda ao pensamento de Vigotski para compreender os modos de pensar próprios da infância. Os resultados nos levam a afirmar que o aprendizado da leitura e da escrita altera os modos de pensar e dizer das crianças; os conhecimentos específicos sobre o sistema de escrita permitiram-lhes realizar novas operaçôes metalinguísticas e metacognitivas. Esse processo evidenciou-se como parte dos processos gerais de aculturação escolar, com ênfase no aprendizado de condutas típicas dessa esfera social.
\end{abstract}

Palavras-chave: Alfabetização. Processo de aprendizagem da leitura e da escrita. Olhares das crianças.

\section{LITERACY: CHILDREN'S VIEWS ON THE LEARNING OF WRITTEN LANGUAGE}

ABSTRACT: The article presents the results obtained from a research with children in their first year of elementary school, in a federal public school, in Rio de Janeiro, during the year of 2011. This research aims to understand the concepts elaborated by children about

Mestre em Educação e professora do Ensino Básico, Técnico e Tecnológico do Colégio Pedro II, Rio de Janeiro. E-mail: angelavidalcp2@gmail.com 
the literacy process, before and after being literate. Interviews were conducted with children, their parents and the classroom teacher. The discourse analysis of the respondents was based on the Theory of Enunciation of Mikhail Bakhtin. Complementarily, Lev Vygotsky's concepts and thoughts were also used to understand the children's own ways of thinking. The results indicate that the learning of reading and writing changes the children's ways of thinking and talking; the specific knowledge of the writing system allowed them to perform new metalinguistic and metacognitive operations. This process is also highlighted as part of the academic acculturation general processes, with emphasis on the learning of typical behaviors of this social sphere.

Key words: Literacy. Learning process of reading and writing. Children's views.

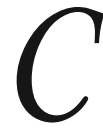

omo uma criança aprende a ler e escrever? Diferentes áreas do conhecimento têm buscado responder a essa questão. E diferentes aspectos dessa aprendizagem têm sido investigados.

$\mathrm{O}$ aprendizado da linguagem escrita requer conhecimentos de natureza fonológica, morfológica, sintática, semântica e pragmática, constituindo-se, assim, num processo bastante complexo a que corresponde grande variedade de abordagens teóricas e metodológicas. Portanto, torna-se essencial, em primeiro lugar, situar nossos estudos no conjunto das propostas que investigam a questão. Começamos por afirmar que o aprendizado da leitura e da escrita se inscreve num processo mais amplo: o das interações discursivas.

Fundamentados em Bakhtin, podemos dizer que, desde o nascimento, mergulhamos no oceano das palavras; somos por elas banhados. É na e pela linguagem que nos constituímos como sujeitos. Nossa existência é essencialmente dialógica; nossos discursos se formam pela assimilação das palavras do outro; nossos enunciados são sempre dirigidos ao outro. Como sintetiza Tezza (2001): "no universo bakhtiniano, nenhuma voz, jamais, fala sozinha" .

Isso não equivale a dizer que não há criação na atividade verbal humana. As palavras alheias serão sempre ressignificadas por cada sujeito, de modo singular. Conforme o próprio Bakhtin (2010, p. 295), "as palavras dos outros trazem consigo a sua expressão, o seu tom valorativo, que assimilamos, reelaboramos, e reacentuamos".

Ler e escrever são atividades dialógicas, de produção discursiva na linguagem escrita. Em pesquisa realizada com alunos em fase inicial de leitura e 
escrita, Goulart e Gonçalves (2013) encontraram evidências de que, mesmo em atividades consideradas específicas para "aquisição do código"2 - como escrita de palavras e frases isoladas -, as crianças estão inseridas numa atividade de interação verbal.

Reduzir a aprendizagem da escrita a um processo perceptivo-motor é um equívoco grave do ponto de vista teórico, com sérias implicações pedagógicas, pois ela é, sobretudo, um sistema complexo de significação. Destituí-la de sua função essencial tem gerado enormes obstáculos ao desenvolvimento cultural das crianças, já que, diferentemente do que ocorre em relação à fala, para aprender a ler e escrever, a grande maioria das crianças necessita de um ensino específico com essa finalidade. Com base em Smolka (1993), reafirmamos a alfabetização como um processo discursivo.

Foi a partir dessa perspectiva que realizamos uma pesquisa com 21 alunos de uma turma do $1^{\circ}$ ano do ensino fundamental, numa escola pública federal do Rio de Janeiro, no ano de 2011, com o objetivo de conhecer o que pensam as crianças sobre o processo de aprendizagem da leitura e escrita antes e depois de serem alfabetizadas. Em outras palavras: como as crianças pensam que se aprende a ler e escrever?

Outras questões se estabeleceram a partir da primeira: o que estaria subjacente às suas respostas - conhecimentos, experiências, crenças? Como se constituiriam essas respostas? $\mathrm{O}$ aprendizado da escrita produziria mudanças nos discursos infantis? Em caso positivo, que caráter teriam essas mudanças? A que fatores poderiam ser atribuídas?

Para responder a essas questôes, decidimos ouvir as crianças. Não quisemos apenas falar sobre elas, mas com elas. Ouvi-las foi uma maneira que encontramos para reafirmá-las como sujeitos, dialogando com seus modos de ver a realidade.

Ouvir o que elas dizem para investigar o que pensam revela um modo de compreender as relaçôes entre pensamento e linguagem. Um dos pressupostos da pesquisa é a centralidade da linguagem, particularmente a linguagem verbal, no processo de formação da consciência. Não nos é possível abordar aqui a natureza dessas relações. Convém apenas destacar que buscamos compreender os modos de pensar das crianças, a partir da análise dos seus discursos, com base em Bakhtin e Vigotski. A teoria vigotskiana foi fundamental para a compreensão dos modos de pensar próprios da infância. 
Foram ouvidos, também, alguns pais e a professora da turma, o que nos possibilitou estabelecer relações entre os discursos das crianças e adultos de sua convivência. Retornamos a Bakhtin (op. cit., p. 332) para afirmar que, na área das Ciências Humanas, o conhecimento se dá na dinâmica da relação eu-outro.

Cada um de nós ocupa uma posição singular no mundo. Dessa posição, podemos ver o mundo de um modo único (e não de um único modo!). Ao mesmo tempo, essa posição não nos permite olhar o mundo como um todo. Não nos é possível sequer enxergarmo-nos por inteiro. Apenas o outro nos vê por completo. Do mesmo modo, somente nosso excedente de visão em relação ao outro pode lhe dar acabamento, pode desvendar aquilo que ele, em sua própria condição, não pode ver.

Se assim é na vida, no âmbito da pesquisa, é preciso buscar o lugar do outro, "mergulhar" nele e dele sair para ver de fora aquilo que ele não pode ver. Mas o pesquisador não pode abrir mão do seu olhar no processo da pesquisa, pois o conhecimento se produz na relação entre "o pesquisador e seu outro" (AMORIM, 2004). Da interação entre os diferentes olhares sobre um mesmo objeto é que se constroem os saberes. Assim se constitui a dialogicidade do processo de produção do conhecimento, seu movimento alteritário.

Cada sujeito pesquisado enunciou a partir do seu olhar. Por outro lado, do meu lugar "de fora", construí sentidos a partir desses diferentes olhares, buscando identificar similaridades, diferenças, possíveis mudanças ao longo do processo, enfim, buscando compreendê-los. Com base em Bakhtin (ibid., p. 381), "chamo sentidos às respostas a perguntas. Aquilo que não responde a nenhuma pergunta não tem sentido para nós".

Foi nesse movimento dialógico com as crianças, com pais e com a professora da turma que buscamos responder às perguntas da pesquisa.

\section{Para que se aprende a ler e escrever?}

Construir uma proposta de análise de discursos com base em Bakhtin tem constituído um desafio para diversos pesquisadores (CUNHA, 2011). O complexo arcabouço conceitual da teoria bakhtiniana não nos permite aplicar mecanicamente categorias estabelecidas a priori. Conforme aponta Brait (2006, p. 61), "as contribuições teórico-metodológicas do pensamento bakhtiniano não configuram, efetivamente, uma proposta fechada e linearmente organizada”. 
Entretanto, ao sugerir uma ciência específica para tratar das relações dialógicas - a Metalinguística -, Bakhtin propõe outra abordagem para os estudos linguísticos, distinta da empreendida pela Linguística tradicional. Estabelecendo o enunciado como unidade discursiva, a teoria bakhtiniana torna necessário incorporar à análise os elementos extraverbais que o constituem.

Em Estrutura do enunciado, Voloshinov (1930, p. 2) apresenta "um esquema condutor" para o estudo desta unidade concreta, que é o enunciado, a começar pela análise das relações de comunicação verbal, que definem as formas de interação verbal. $\mathrm{O}$ autor afirma que essas relaçôes têm origem na organização econômica da sociedade. Tal organização é objeto de estudo das ciências sociais, cabendo ao estudioso da linguagem incluir em suas análises o conhecimento das relações sociais de comunicação, para compreender as formas de interação verbal.

Desse modo, nossa análise partiu dos discursos das crianças e de suas famílias em que se explicitaram claramente os valores subjacentes à sociedade de que fazem parte: uma sociedade dividida em classes, em que as desigualdades socioeconômicas impedem o acesso de muitos aos bens materiais e culturais de valor para essa sociedade. Ascender socialmente torna-se meta dos que desejam usufruir da posse desses bens. No entanto, os postos de trabalho de maior remuneração são reservados aos mais "capacitados", segundo o ideário neoliberal. Como analisa Frigotto (2001, p. 14),

[...] reafirma-se a ética utilitarista e individualista do liberalismo conservador. Justifica-se a exclusão e a desigualdade como elementos necessários à competitividade. Busca-se firmar uma consciência alienada de que os vencedores ou os incluídos devem-no a seu esforço e competência.

A era do capitalismo globalizado, assentado em bases científico-tecnológicas, caracteriza-se pela diminuição dos postos de trabalho resultante da substituição do homem pela máquina. No plano ético-político, seus defensores afirmam que não há outro caminho possível para a vida social humana. À sombra dessa concepção, resta ao indivíduo esforçar-se para ser competitivo, lutar para tornar-se empregável.

$\mathrm{Na}$ "era do conhecimento", a escola é vista como lugar de formação para o desenvolvimento de competências e habilidades que permitirão, aos mais "bem-sucedidos", acesso a uma formação acadêmica mais completa, com 
Alfabetização: o olhar das crianças sobre o aprendizado da linguagem escrita

respectivo acesso aos "melhores" empregos. Os que não se mostrarem aptos o suficiente para essa progressão, ficarão com os postos menos ambicionados, porque menos reconhecidos econômica e socialmente. O conhecimento se reduz a um instrumento para a empregabilidade, vinculado necessariamente ao mundo do trabalho. $\mathrm{O}$ discurso neoliberal se impóe como verdade inquestionável.

Esse ideário pôde ser identificado claramente nos discursos dos pais entrevistados e de algumas crianças. Quando terminamos a primeira entrevista com Roberta, ${ }^{3}$ em maio de 2011, perguntei se ela gostaria de dizer mais alguma coisa. Segue trecho de nossa conversa: ${ }^{4}$

Não sei se eu quero. Sobre outro assunto, o que você quiser falar. Eu quero falar uma coisa. Então, fala. Eu também sei que tem que estudar pra ficar rico, pra ter dinheiro... É só? É. Mas eu também sei de mais uma coisa: que a gente tem que estudar bastante pra trabalhar, pra ter alguma coisa na vida. Quem diz isso pra você? Minha mãe e meu pai.

Os valores que sustentam ideologicamente o atual modelo de sociedade também puderam ser ouvidos nas respostas que algumas crianças deram à questão "Para que a escola ensina a ler e escrever?":

"Pra gente trabalhar... quando crescer...". (Erik)

“...pra ganhar dinheiro”. (Gabriela V.)

“...pra gente aprender a ganhar dinheiro”. (Letícia)

"Pra gente poder ter din din”. (Gabriela G.)

A ideologia é um dos conceitos fundamentais da arquitetônica bakhtiniana, e a análise da (re)produção da ideologia nas relações cotidianas constam da pesquisa. A questão fica aqui apontada para que se leve em conta que elementos macroestruturais estão presentes nos enunciados que foram analisados.

Aproximadamente 19\% do total das crianças entrevistadas responderam à pergunta feita anteriormente, relacionando o aprendizado da linguagem escrita ao mundo do trabalho ou à possibilidade de obtenção de dinheiro. Mas, para a maioria (cerca de 57\%), esse aprendizado exerce uma função imediata, qualificando-as de algum modo, seja por deixarem-nas "espertas", "inteligentes", seja por lhes darem um saber que não tinham: saber "ler", saber "falar direito", saber "fazer contas". Para uma parcela menor, mas expressiva 
(aproximadamente 40\%), esse aprendizado garantirá êxito na continuidade da atividade acadêmica ou na vida, de um modo geral:

"A gente poder se formar... Ir pra faculdade...". (Ana Cecília)

"Pra quando a gente tiver lááá com o Pedrão, ${ }^{5}$ a gente saber ler e escrever". (Zik)

"Pra quando você for adulto, aí você tiver andando sozinho, aí se tiver uma placa, aí você lê, aí você vai saber que não pode ir". (Rafael)

Um percentual menor de crianças (em torno de $24 \%)^{6}$ relaciona o aprendizado da linguagem escrita unicamente à vida escolar atual:

"Porque a gente precisa escrever pra fazer todos. (...) Todos os dever, todos os deveres". (Colérus)

"Porque, pra... pra passar de ano". (Gabriel)

Algumas crianças deram respostas que, numa primeira leitura, parecem tautológicas, como, por exemplo, a de Alice F.: Porque pra gente saber ler e escrever. Insistimos, perguntando: "Pra quê?" e ela disse: Pra gente ler. Para nós, essa não é uma resposta circular. Alice F. parece reconhecer que o aprendizado da leitura e da escrita, tal como o conhece, não tem um objetivo em si mesmo, mas é um instrumento para a efetiva atividade de leitura: a leitura em situações reais da vida.

Bernardin (2003) questiona se os debates críticos sobre a aprendizagem da leitura nas últimas décadas transformaram as práticas pedagógicas de modo significativo. Com base no Relatório da Inspeção Geral da Educação Nacional da França (FRANCE, 1995), ele afirma que, apesar de se observar uma preocupação em associar "o acesso ao sentido" ao domínio do sistema de escrita, ainda pode ser constatada uma quase geral ausência de articulação entre as atividades referentes a um ou a outro propósito, privilegiando-se as relativas à apropriação do sistema.

O percurso metodológico descrito pela professora da turma de Alice durante a entrevista prevê uma gradação em que o texto, como unidade de trabalho, só é abordado após a análise de letras, sílabas e palavras, na suposição de que só com o domínio das unidades menores é que os alunos estarão prontos para o trabalho com textos.

É possível que isso tenha levado essas crianças a entenderem que as atividades que realizavam com letras, sílabas e palavras não eram propriamente 
de leitura e de escrita, mas que lhes permitiriam saber ler e escrever no futuro, seja um futuro próximo - o final do ano -, seja um futuro distante (na faculdade, quando forem adultas).

De qualquer modo, todas as crianças atribuíram, em pelo menos uma das entrevistas, um papel importante ao aprendizado da linguagem escrita. Essa importância parece mais evidente para aqueles que iniciaram o ano sem estarem alfabetizados. Quando perguntamos se esse aprendizado havia mudado alguma coisa em suas vidas, $40 \%$ das que iniciaram o ano alfabetizadas responderam que sim. Entre as que começaram o ano afirmando não saber ler e escrever, o percentual aumenta para mais de $83 \%$. Há uma mudança de status na própria classe. Essa mudança ganha importância na/ para a vida social:

“... porque antes eu não sabia, agora eu tô sabendo”. (Lucas P.)

“... porque agora, a minha mãe, tem vezes, pede pra eu ler um livro pra ela, e... fica mais fácil de ler e escrever agora”. (Gabriela C.)

“... quando eu tô na rua, quando meu pai freia, eu fico lendo o que tem nas placas". (Gabriel)

Algumas crianças falam da satisfação emocional proporcionada por essa conquista:

Mudou alguma coisa na sua vida, aprender a ler e escrever? Que eu já sei ler. E isso fez que diferença pra você?? O que mudou na sua vida por causa disso? Que eu tô feliz. (Gabriela V.).

$\mathrm{O}$ que mudou? Eu queria ler muito e queria escrever muito. E agora você já consegue? Hum-hum. Você está feliz com isso? Eu tô muito feliz! (Zik)

As crianças sabem que o aprendizado da leitura e da escrita muda sua posição no grupo social, mesmo sem saberem ainda avaliar plenamente o que representa para esta sociedade o acesso à cultura letrada.

\section{Como se aprende a ler e escrever}

Esse foi o principal objeto de investigação de nossa pesquisa. Tendo nos proposto a ouvir as crianças para conhecer suas concepçōes sobre o processo de aprendizagem da leitura e da escrita, tínhamos uma expectativa: supúnhamos que, assim como elaboram ideias sobre o sistema de escrita 
por fazerem parte de uma cultura letrada, acreditávamos que também elaborariam concepçôes sobre o modo pelo qual se aprende a ler e escrever. Mais ainda: imaginávamos que as crianças fariam referências a práticas de leitura e de escrita, citando material de leitura (livros, revistas, cadernos) e/ ou objetos utilizados na escrita (lápis, caneta, papel).

Tentando relacionar seus discursos às suas experiências de vida, perguntamos a elas sobre suas vivências escolares anteriores e sobre atos de leitura presenciados (ou não) no ambiente doméstico.

$\mathrm{Na}$ primeira etapa das entrevistas com as crianças, ao responderem à questão: "Você já sabe ler e escrever?", oito crianças afirmaram que sim, sete disseram saber ler e escrever parcialmente ("mais ou menos", "um pouquinho", "escrever, eu sei; ler, não") e seis negaram saber ler e escrever.

Analisando as respostas das crianças à questão "Como se aprende a ler e escrever?", 7 observamos que 14 (dois terços do total) fizeram referência a pelo menos algum elemento linguístico (letra, som, sílaba, frase); duas referiram-se a processos mentais ("pensando"), cinco citaram aspectos atitudinais ("prestando atenção", "se esforçando", "estudando", "ficando quietinho") e apenas uma mencionou uma prática de leitura ("lendo livro"), tendo também se referido a um elemento linguístico, razão por que o total de respostas é maior que o número de alunos.

Observando os resultados, pudemos verificar que $90 \%$ das crianças alfabetizadas referiram-se a, pelo menos, um elemento linguístico e nenhuma a aspectos atitudinais nas explicações que elaboraram. Entre os que diziam saber ler e escrever parcialmente, o percentual é de $60 \%$ e entre os que afirmavam não saber ler e escrever, o percentual cai para cerca de $30 \%$.

Notamos que entre as crianças alfabetizadas a referência a elementos linguísticos é muito mais alta do que entre os que menos sabem sobre o sistema de escrita. Essa conclusão confirma e é confirmada por um estudopiloto que realizamos em 2010.

Há uma clara correlação entre o conhecimento do sistema de escrita e a citação de elementos linguísticos. Ao aprenderem a ler e escrever, as crianças vão se apropriando de conhecimentos que lhes permitem operar nos níveis metalinguístico e metacognitivo:

"A tia... A tia pediu, do ano passado, pediu caderno de caligrafia. Aí ela foi botando... o... é... vogal por vogal... depois sibala por sibala [sic], depois ela fez frases. [...] Assim que eu aprendi”. (Gabriela G.) 
Alfabetização: o olhar das crianças sobre o aprendizado da linguagem escrita

"É... Porque agora eu aprendi. Eu fui a... eu fui... eu tenho alguma coisa... e eu faço... e aí eu escuto o som. [...] Eu falava uma coisa e escutava o som pelo ouvido. E como você aprendeu as letras? Qual letra que era o B, qual letra que era o Q... As maiúsculas e minúsculas”. (Nei)

"Na minha escola antiga a professora, é... aos pouquinhos, ela ia dando umas letras, pra eu poder botar a letra A e, depois, a gente fazia na ordem certa, tipo: igual as vogais: A, E, I, O, U. Ela começava do A, depois do $\mathrm{B}$, a gente aprendia a fazer na letra cursiva. Aí fui começando a aprender e agora já escrevo letra cursiva”. (Tatiana)

"Ah, eu acho que, pra escrever, é repetindo sons. [...] Se eu quero escrever "escada", eu tenho que repetir "escada", aí eu vejo qual é a primeira letra". (Rafael)

Na segunda etapa das entrevistas, perguntamos às crianças que se alfabetizaram ao longo do ano como aprenderam a ler e escrever. Quase todas passaram a se referir a práticas de leitura e de escrita e/ou a elementos linguísticos, como por exemplo:

"Eu aprendi estudando lá na... em casa, lendo livro... e... fazendo... coisas. Ai, é... estudando... fazendo... escrevendo”. (Alice L.)

"Eu fiquei praticando ler, praticando escrever, aí consegui. E como é que pratica ler e escrever? Lendo um livro e... vendo... é... sílabas pra escrever". (Gabriela C.)

"Com a tia". Com a tia? Como que ela ensinou? "Ela ficava mandando ler os pedacinhos". Lia por pedacinhos? "É". E como você aprendeu a escrever? "Ué, por causa que, quando eu vejo as coisas, aí, aí eu lia, aí eu escrevia igual". (Zik)

O trabalho com a linguagem escrita modificou os modos de pensar e dizer dos sujeitos investigados. $\mathrm{O}$ desenvolvimento da fala/do pensamento das crianças foi alterado pelas interações discursivas de que participaram. Desafios cognitivos lhes foram oferecidos no fluxo da comunicação verbal.

As análises dos nossos diálogos com as crianças nos permitiram captar alguns momentos em que identificamos o movimento da palavra ao pensamento e do pensamento à palavra, da teoria vigotskiana.

Quando perguntei a João Vítor quando era hora, na vida de uma criança, de ela começar a aprender a ler e escrever, ele respondeu: Hum... Dentro da minha cabeça, tem um monte de "macaquinho pensando...". $\mathrm{O}$ menino fala de um processo de elaboração do pensamento e do discurso que 
ocorre "dentro de sua cabeça", provocado pela questão proposta. Um novo enunciado: "Com quantos anos vocês acha que uma criança deve aprender a ler e escrever"? Uma nova resposta: Com seis ou sete.

Erik deixa ainda mais claro o surgimento de uma questão nova para ele:

E pra quê que a escola ensina a ler e escrever? "Eu vou ver ainda, que eu não pensei, como a escola...”. É, pra quê? Pra que a gente tem que aprender isso? Pra quê que a gente tem que aprender a ler e escrever? "Porque se não, aí a gente não aprende nada, e aí a gente não consegue falar nada, e não consegue entender nada, e aí fala errado: vlá, vlá, vlu, vlu, vlu”.

Erik diz que não havia pensado ainda sobre a questão que propusemos. Contudo, nossa enunciação provocou uma resposta, permitindo a construção de ideias/discursos novos, de novos sentidos.

Recuperar, por meio da linguagem escrita, nossos diálogos com as crianças nos permitiu dar visibilidade ao movimento alteritário do discurso, em que, na dialética relação entre pensamento e linguagem, o outro assume papel fundamental.

\section{Outros modos de dizer - o que as crianças disseram desenhando}

Compreendendo que a linguagem não verbal é um importante modo de dizer das crianças menores, pedimos aos alunos que desenhassem uma criança aprendendo a ler e escrever.

Esse procedimento se mostrou muito produtivo para a nossa pesquisa. De fato, em seus desenhos puderam ser observados elementos novos, que não haviam sido mencionados nas entrevistas.

Quando analisamos as respostas das crianças à questão "Como se aprende a ler e escrever?", afirmamos que, entre as que iniciaram o ano alfabetizadas, nenhuma fez referência a aspectos comportamentais. Ao explicarem, no entanto, o que haviam desenhado, quatro disseram ter desenhado alguém "prestando atenção à professora" ou "levantando o dedo para falar".

Inversamente, observamos que as crianças que afirmaram nas entrevistas não saberem ler e escrever referiram-se, em sua maioria, a aspectos atitudinais. Em seus desenhos, porém, todas representaram situações escolares, em que se mostram suportes de textos (livros, quadro de giz com rabiscos 
simbolizando a escrita), objetos para a escrita (lápis, caderno) e símbolos matemáticos (algarismos, sinal de igualdade).

Gabriela C. é uma dessas crianças. Em nossa primeira conversa, ela disse que uma criança aprende a ler e escrever prestando atenção à professora. Em seu desenho (Figura 1), porém, há uma menina sentada na cadeira e, sobre a mesa, encontram-se objetos para escrita (um lápis ou uma caneta e um caderno ou livro). Destaca-se também a figura da professora, próxima a ela.

\section{Figura 1}

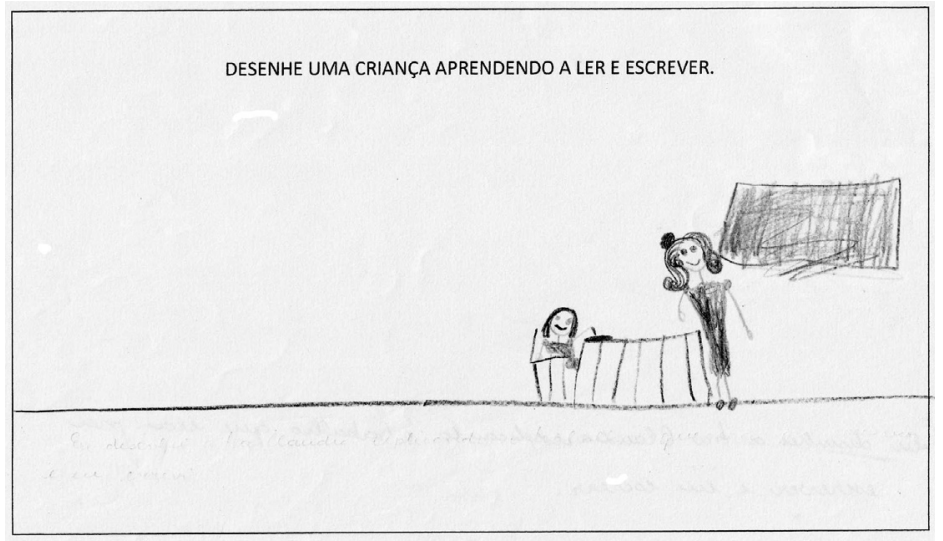

Trata-se de uma prática escolar de escrita. O que Gabriela C. não disse com palavras, disse desenhando.

Assim como ela, as outras crianças tiveram a oportunidade de dizer com desenho. Das 21 crianças da turma, vinte representaram práticas de leitura e escrita (escolares ou sociais, no sentido mais amplo) em seus registros.

Nossa expectativa inicial de que, ao serem perguntadas sobre o processo de alfabetização, as crianças fariam referência a práticas culturais de leitura e de escrita não era sem fundamento. Seria necessário, no entanto, permitir-lhes outros modos de dizer.

A relação entre aprendizagem da leitura e da escrita e aspectos que envolvem as atitudes dos alunos no ambiente escolar se revelou mais 
complexa. Roberta, por exemplo, alfabetizada no início do ano, relata, em nossa primeira conversa, que sua professora anterior colocava letras no quadro. Fez referência, portanto, a um elemento linguístico. Em seu desenho (Figura 2), podem ser vistas as letras A, B e C no quadro de giz. No entanto, ao me explicar o que desenhou, disse: "Eu desenhei a menina prestando atenção à professora".

\section{Figura 2}

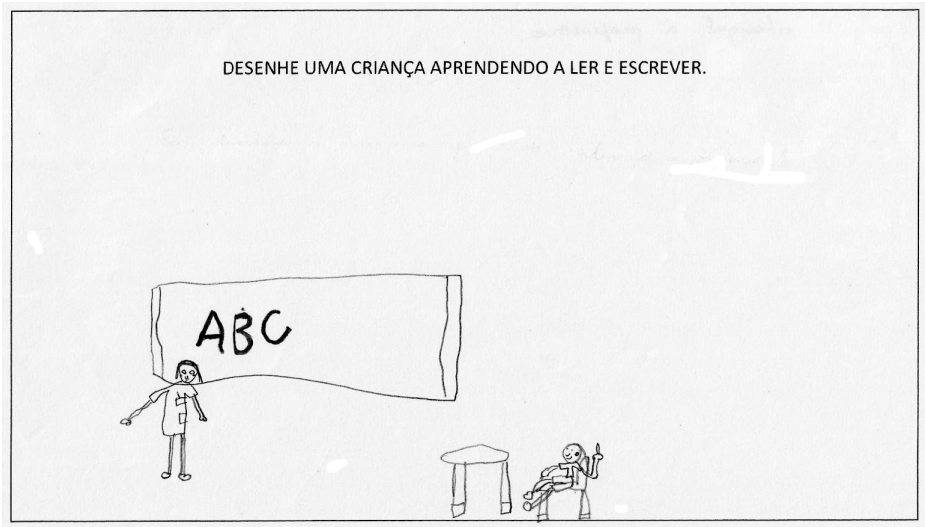

A associação entre aprendizado escolar e comportamento na escola constituiu importante aspecto do nosso trabalho e foi aprofundada na pesquisa, em que abordamos algumas questóes relativas ao processo de aculturação escolar. Pelos limites deste artigo, não será possível tratar dessas questōes aqui.

Mas quais as implicações dos resultados a que chegamos? Qual a importância de conhecermos o que pensam as crianças sobre o processo de alfabetização e as mudanças que observamos nos seus modos de pensar/ dizer durante o processo?

Em relação especificamente ao aprendizado da leitura e da escrita, as evidências de que a aprendizagem da linguagem escrita permite às crianças novas formas de pensar e de dizer reafirmam nosso compromisso com a educação brasileira, particularmente com a educação pública brasileira, no sentido de continuar trabalhando pela inserção de todas as crianças no 


\section{mundo da cultura letrada. Elas reafirmam nossa crença de que todas têm o direito de aprender a ler e escrever.}

Quanto às questóes relativas ao processo de aculturação escolar em geral, evidencia-se a necessidade de se ter clareza de que o conhecimento não se constrói fora da dinâmica das relaçôes sociais. É algo que se produz na relação entre o eu e o outro (muitos outros), portanto, no universo dos signos, o que implica dizer, na teoria bakhtiniana, dos valores. A serviço da construção de que valores trabalha a escola? Que projetos de sujeito e de sociedade subjazem às diferentes práticas pedagógicas? Essas são questôes fundamentais que precisam estar sempre em discussão.

\section{Essa é a dimensão ética do fazer científico!}

\section{Notas}

1. Texto disponível online.

2. A expressão aparece entre aspas porque, conforme Morais (2005), a escrita alfabética não é um código, mas um sistema notacional. Essa é uma importante e complexa discussão, que não será aqui realizada. Ainda assim, preferimos utilizar o termo código, bastante comum nos textos sobre alfabetização, para facilitar a compreensão dos leitores.

3. Os nomes das crianças não são reais. Foram por elas escolhidos durante o processo da pesquisa.

4. Compreendendo o texto como a materialidade do discurso, transcrevemos nossos diálogos com as crianças de modo que seu registro no papel - o seu aspecto material - pudesse ser o mais preciso possível. Registramos as falas, buscando preservar as marcas de singularidade dos sujeitos e da eventicidade dos enunciados. Visando à coerência com os princípios bakhtinianos da pesquisa, não separamos a fala do entrevistador e do entrevistado, alternando os parágrafos e identificando-os no começo com os nomes ou iniciais dos interlocutores, de acordo com a formatação convencional. Escrevemos o texto num continuum, posto que a interação se dá no fluxo da comunicação verbal. Como os enunciados são determinados pela alternância dos falantes, colocamos em itálico os enunciados de nossos interlocutores para melhor identificá-los. Essa forma de registrar os diálogos parece corresponder melhor às ideias de nossa proposta de pesquisa.

5. Modo como são chamadas, no interior da instituição onde estudam, as unidades escolares dos anos finais do ensino fundamental e do ensino médio.

6. A soma dos percentuais excede $100 \%$ pelo fato de algumas crianças, ao responderem, apresentarem mais de uma ideia.

7. Às crianças que já dominavam o princípio alfabético de nossa escrita, a pergunta proposta foi "Como você aprendeu a ler e escrever?".

8. É possível que a imagem utilizada por João Vítor tenha sido inspirada no livro $O$ menino maluquinho (ZIRALDO, 2010). Nele, a expressão "tinha macaquinhos no sótão", que caracteriza o personagem principal, é ilustrada por um desenho em que macaquinhos pulam dentro da cabeça do menino. As crianças tiveram acesso ao livro. 


\section{Referências}

AMORIM, M. O pesquisador e seu outro: Bakhtin nas ciências humanas. São Paulo: Musa, 2004.

BAKHTIN, M. Estética da criação verbal. Trad. de Paulo Bezerra. São Paulo: Martins Fontes, 2010.

BERNARDIN, J. As crianças e a cultura escrita. Porto Alegre: Artmed, 2003.

BRAIT, B. Uma perspectiva dialógica de teoria, método e análise. Gragoatá, Niterói, n. 20, p. 47-62, 2006.

CUNHA, D. Formas de presença do outro na circulação social dos discursos. Bakhtiniana, São Paulo, v. 1, n. 5, p. 116-132, 2011.

FRANCE. Ministère de l'Education Nationale. Inspection Générale de l'Education Nationale. L'apprendissagem de la lecture à l'école primaire: bilan et perspectives: analyse des difficultés, des échecs et des réussites. Paris: MEN, 1995.

FRIGOTTO. G. Educação, crise do trabalho assalariado e do desenvolvimento: teorias em conflito. In: FRIGOTTO, G. (Org.). Educação e crise do trabalho: perspectivas de final de século. Petrópolis: Vozes, 2001. p. 25-54.

GONÇALVES, A.V. Alfabetização: o olhar do sujeito aprendiz. 2012. Dissertação (Mestrado em Educação) - Departamento de Educação, Universidade Federal Fluminense, Niterói.

GOULART, C.M.A.; GONÇALVES, A.V. Aspectos semióticos da aprendizagem inicial da escrita. In: GOULART, C.M.A.; WILSON, V. Aprender a escrita, aprender com a escrita. (orgs.) São Paulo: Summus, 2013.

SMOLKA, A.L.B. A criança na fase inicial da escrita: a alfabetização como processo discursivo. São Paulo: Cortez, 1993.

TEZZA, C. A construção das vozes no romance. In: BRAIT, B. Bakhtin, dialogismo e construção do sentido. Campinas: Unicamp, 2001. Disponível em: http://cristovaotezza.com.br/textos/palestras/p_vozesromance.htm Acesso em: 25 jul. 2007. 
Alfabetização: o olhar das crianças sobre o aprendizado da linguagem escrita

VOLOSHINOV, V. Estrutura do enunciado. Trad. de Ana Vaz, para fins didáticos. In: TODOROV, T. Mikhail Bakhtin: le principe dialogique. Paris: Seuil, 1981. (1930).

ZIRALDO. O menino maluquinho. São Paulo: Melhoramentos, 2010.

Recebido em 30 de setembro de 2012.

Aprovado em $1^{\circ}$ de março de 2013. 